\title{
A Mobile Toolkit for Placement Learning
}

\author{
Pei Zhang, David E. Millard, Gary B. Wills, Yvonne Howard, Sue J Faulds*, \\ Lester Gilbert, and **Dan Sparks \\ School of Electronics and Computer Science, University of Southampton, UK \\ \{pz, dem, gbw, lg3, ymh\}@ecs.soton.ac.uk\} \\ *School of Nursing and Midwifery, University of Southampton, UK S.J.Faulds@soton.ac.uk \\ **Thames Valley University Dan.Sparks@tvu.ac.uk
}

\begin{abstract}
Students whose professional qualifications are gained through work placement-based learning are assessed as to their competency to carryout tasks. These students are usually supported by mentors, qualified practitioners who regularly meet with them and give feedback on their progress. This support can be highly variable, affecting the quality of the students' learning experience. Through a process of co-design the mPLAT project has created a mobile toolkit to connect students' placement experiences with the professional competency model that they are assessed against. The toolkit does this by matching their learning requirements to a placement and producing an Action Plan that acts as a focus for their reflection and for their meetings with their mentors.
\end{abstract}

Keywords: mobile, work placement, competency

\section{Introduction}

Students undertaking courses in higher education for professional qualifications generally undertake a number of work placements during their training (for instance, health care professionals). During these placements the students are assessed as to their level of competency at completing certain tasks by a qualified practitioner. Ideally this is supported by regular meetings in which the student is given ongoing feedback. However, all too often the pressure of workload on the supervising practitioner means that the support and assessment processes can be fragile, resulting in the students receiving little or no feedback on their progress, which in turn impinges on the students' learning. Also, with students being away from their normal place of learning, they can be without their support networks and find it difficult to access learning resources.

Other projects that have looked at supporting learning through mobile devices have built large systems that integrate information in a fixed and pre-designed way. For example, the Nightingale Tracker [6] uses a central database and provides data and communication tools built around it, while the Chawton House project uses a sophisticated orchestration engine to drive an outdoors learning experience based on proprietary activity cards [7]. However, such whole-system approaches are inherently heavyweight and inflexible, and has led to criticisms that mobile learning is technology-led and pedagogically naïve [5]. Standalone tools such as the "ME" mobile workbook [2], or the cell-phone English vocabulary trainer [1] offer a simpler alternative that fits with existing practices more flexibly, though these tools lack the integration qualities of the whole-system approach

In this paper we present the Mobile Placement Learning and Assessment Toolkit (mPLAT), which contains a number of loosely-coupled tools that enable students on placements to connect their work experiences with their learning outcomes in order to aid planning and reflection. We developed the toolkit through a case study with the Nursing and Midwifery, and Healthcare departments in three different UK Higher Education Institute (HEIs) (the University of Southampton, Thames Valley University, and the Bournemouth and Poole College). This provided a range of users including traditional universities, new universities and those undertaking Higher Education courses in Further Education colleges.

\section{Background to the Case Study}

Pre-registration nursing students spend $50 \%$ of their 3year programme in clinical practice undertaking a series of placements in different areas of the healthcare system. Whilst in placement, students are supported by mentors who assess the students' competences in practice against a set of learning outcomes detailed in the practice assessment handbook or practice portfolio. These learning outcomes form a Competency Model, a complex network of Skills and Proficiencies, against which students will be assessed. Nurses are expected to be able to demonstrate 
skills and proficiencies both independently, and also with an awareness of how they connect to each other.

During their placements students complete a preliminary, an interim, and a final interview with their mentors. In these interviews they discuss the action plans the students need to follow and progress the students have made. This good practice feature of induction, interim, and final assessment is common to most educational situations where students experience work-based learning.

The HEI has a responsibility to assure the quality of the assessment process in practice placements as well as within the HEI itself. In order to achieve this, the HEI has a duty to ensure that mentors are well-informed about the assessment process and the curriculum that students are following. This is a major challenge due to the large numbers of mentors (up to several thousand for any HEI), the fact that mentors have difficulty finding time to attend update meetings on the assessment process and curriculum due to pressures in their workplaces, and their distribution across a typically wide geographical area.

Issues around ensuring that students are fit for practice at the point of registration were brought home recently following a report by Duffy [3] which found that mentors were reluctant to fail students due to a number of factors, including lack of confidence, concerns over personal consequences (for student and self), and leaving it too late to implement formal procedures (the preliminary and interim interviews missed or undertaken so late that action plans to assist a student who was not progressing could be satisfactorily implemented).

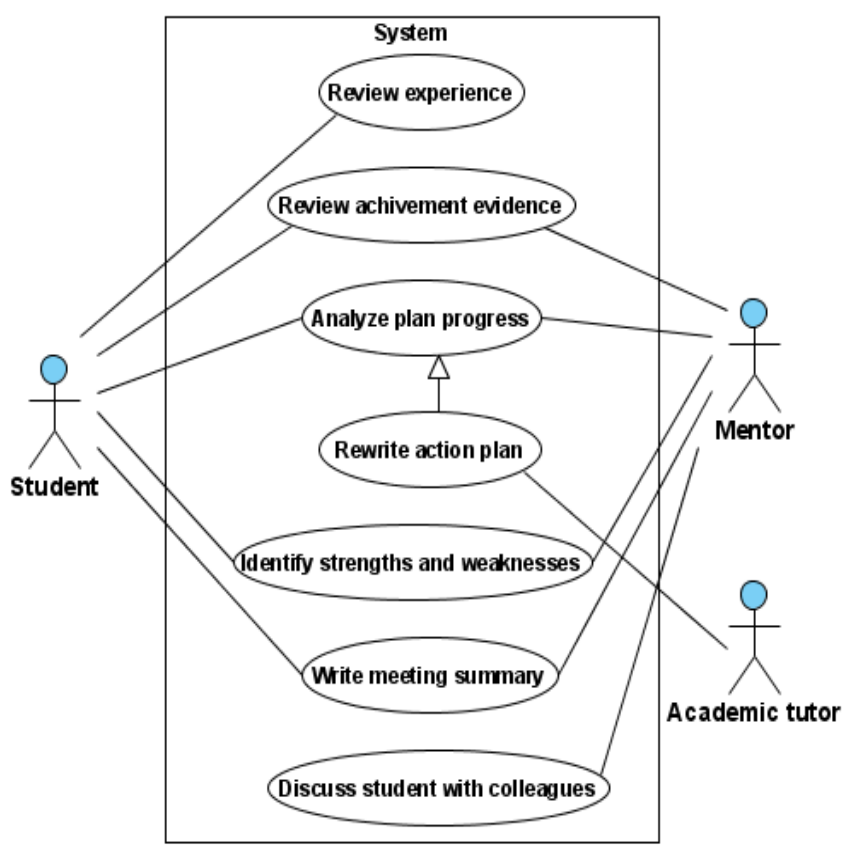

Figure 1: Use Cases for the Toolkit

\section{Design of the Toolkit}

At the beginning of the project we engaged with users in a co-design process to ensure that we were addressing real problems with realistic solutions. The end-users developed personas and scenarios [4] used to highlight the problems they had in using the current paper based system. These were refined in a number of design workshops to exemplify the interactions required.

The workshops also identified the need for a tool that allows students to identify their strengths and areas for improvement against the competencies model defined in their practice handbook, and by using the learning opportunities identified by their mentor, to create an action plan (learning agreement). This could then be used in subsequent meetings with the mentor to monitor progress.

From the co-design sessions, personas, scenarios and the competency profile of the student user, we were able to create story boards for the tools quite quickly. Figure 1 shows the use case diagram for the system, which was supported by normal and alternative use scenarios.

Rather than just provide a tool that mimicked the multiple views of the competency model afforded by the paper-based practice handbook, we wanted to provide functionality that supported the preparation for, and activities during, the initial meeting wherein an Action Plan was created by the student and mentor. As modeled in the use case and activity diagrams, the stages of this process are:

1. Preparation

a. Student prepares by self-assessment of strengths and weaknesses.

b. Mentor prepares by creating a placement profile.

2. Initial Meeting

a. Student and Mentor discuss student's learning needs.

b. Student and Mentor negotiate an Action Plan based on student's learning needs and the available learning opportunities within the placement.

The toolkit therefore consists of 3 main parts:

1. Student self-assessment

2. Mentor placement profile creation

3. Student / Mentor Action Plan creation

The Student's Self-Assessment and the Mentor's Placement Profile are compared by the system in order to build an Action Plan for the student that is both useful and practical for the individual student's needs in their current placement. 


\subsection{Competency Framework}

The students currently use a paper-based practice handbook to record the assessment of their competencies. The HEIs required this to remain the summative record of the students' progress. The development team's first task was to understand the structure of the competency and skills framework embedded in the practice handbook by mapping key concepts and relationships. This is shown in Figure 2.

The main concepts represented in the structure as separate entities were those of proficiency, subproficiency, skill, and sub-skill. The relationships in the structure are the mappings between proficiencies and skills, between proficiencies and sub-proficiencies, and between skills and sub-skills.

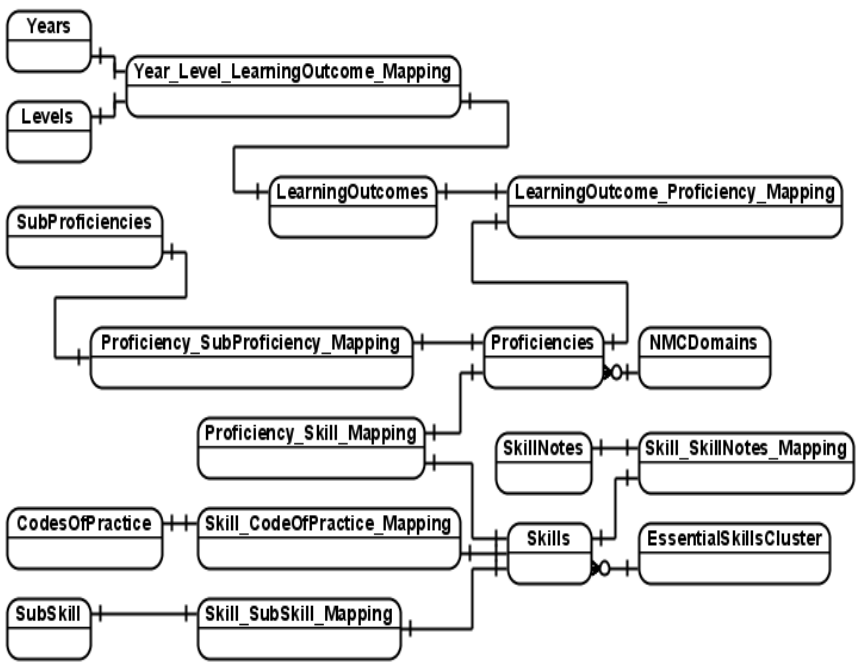

Figure 2: Competency and Skills Structure

\subsection{Placement Profile}

The mentor's placement profile provides the basis for developing a realistic action plan for a given work context. Figure 3 shows the mentor's placement profile data schema. For each placement, our tool lists available learning opportunities and learning examples from which the mentors can choose the appropriate set for a particular student and then adds them to the placement profile. These learning opportunities and examples are linked with proficiencies and skills in the portfolio.

\subsection{Self-Assessment and Action Plan}

Figure 4 shows the student's self-assessment and action plan schema. The Self-Assessment model provides the information structure for the tool supporting the student's own reflection on their strengths and weaknesses. It maps the students' rating of their ability to complete a proficiency and/or perform a skill and also a self-written comment on the rating they have selected. The action plan connects the student's self-assessment with a placement profile. It consists of the learning outcomes for the placement, the student's self assessment of their strengths and weaknesses, the competencies required to be met, and the mentor's assessment of what learning experience the placement offers.

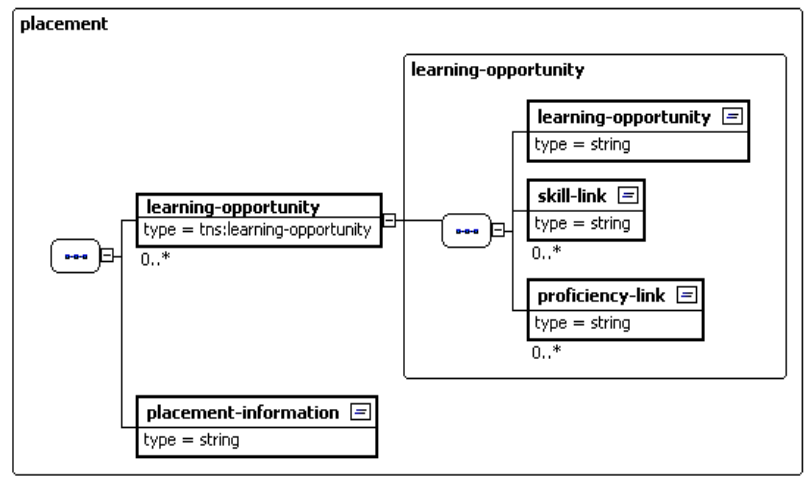

Figure 3: Placement profile Schema

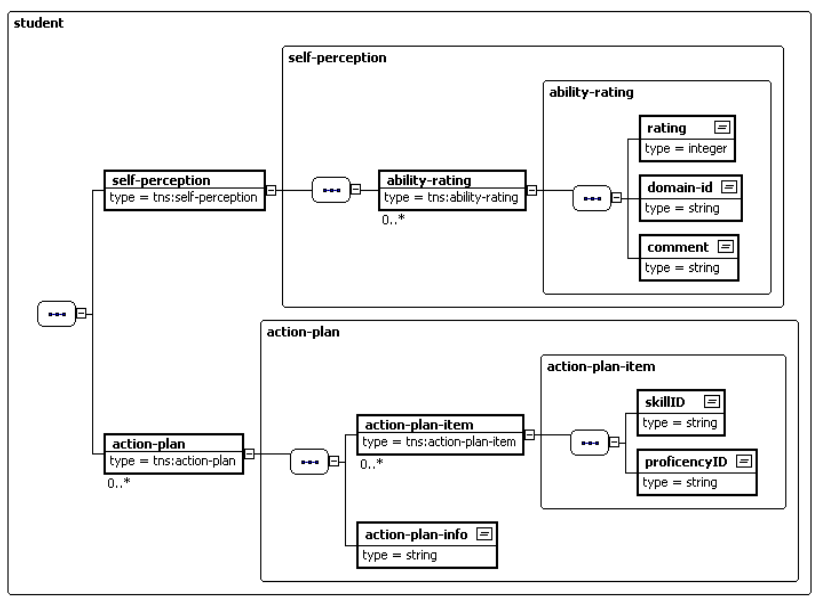

Figure 4: Action plan creation schema

\section{Implementation}

The toolkit has been created using Visual Studio .NET for Windows Mobile 5 and we assumed a screen resolution of $320 \times 240$.We produced two mobile applications, a Self-Assessment Tool and an Action Plan Builder (as well as Web tools to help mentors create the Placement Profiles).

\subsection{Self-Assessment Tool}

Before the initial meeting with mentors in a specific placement, students need to reflect on their progress towards competent practice. Our first tool supports this self-assessment by allowing students to rate their strengths and weaknesses in the achievement of the proficiencies 
and skills from the practice handbook. Students can view all the proficiencies and skills as well as sub-proficiencies (Figure 5). They rate each skill or proficiency from 1 to 5, then add their most needed proficiency into their selfassessment form. In addition, they can add their own comment. Once the form is finished, it can be saved as an html page or xml file, which will be used in creating the action plan. This rating and commenting functionality helps students to clarify their own learning needs.

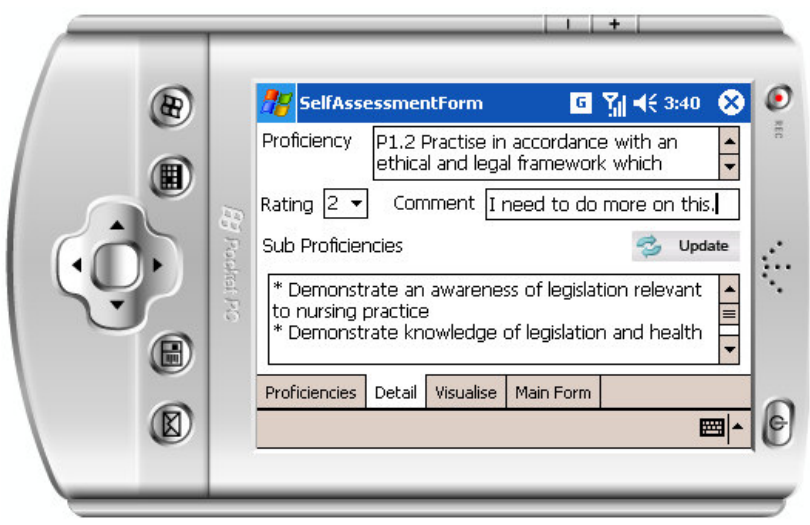

Figure 5: Self-assessment form

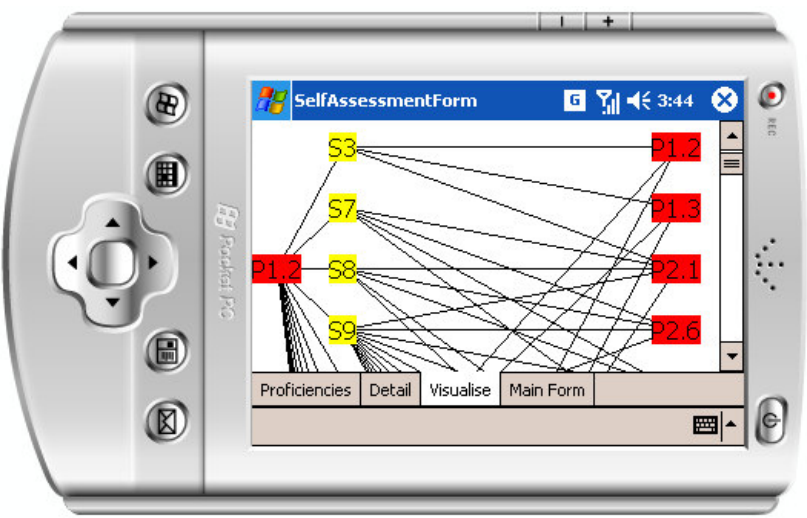

Figure 6: Visualization of Competency Network

During this process, a visualization function may be accessed to help students uncover the interconnectedness of the proficiencies and skills and support their better understanding of the whole competency and skills framework (Figure 6). An API, PocketPiccolo.NET ${ }^{1}$, was used to draw proficiency and skill nodes with edges between them. The graph of the relationships between proficiencies and skills is a useful way to represent the large amount of information, which is not clearly identified in the paper-based handbook.

\footnotetext{
${ }^{1}$ Piccola API (Jan, 2008): http://www.cs.umd.edu/hcil/jazz/
}

\subsection{Action Plan Builder}

During the first placement supervision meeting, the students need to negotiate an action plan with mentors. The action plan tool helps them create the appropriate action plan. Students need to upload their self-assessment file and the mentor's placement profile (created for each placement prior to the student's arrival), which shows what learning experience is available on this placement.

The tool then filters proficiencies by rating scores. For example, Figure 7 shows the proficiency P1.3 which is rated as 3/5. The tool also lists available learning experiences associated with a specific proficiency in this placement (Figure 8). The tool gives direct links between student's learning needs and available learning opportunities, which helps the student and mentor to decide which items can be added into the final action plan (Figure 9).

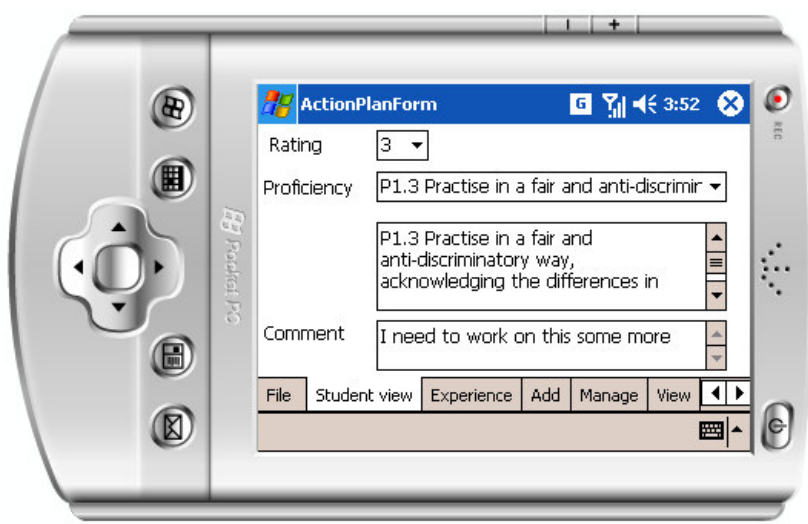

Figure 7: Action Plan (Student Creation View)

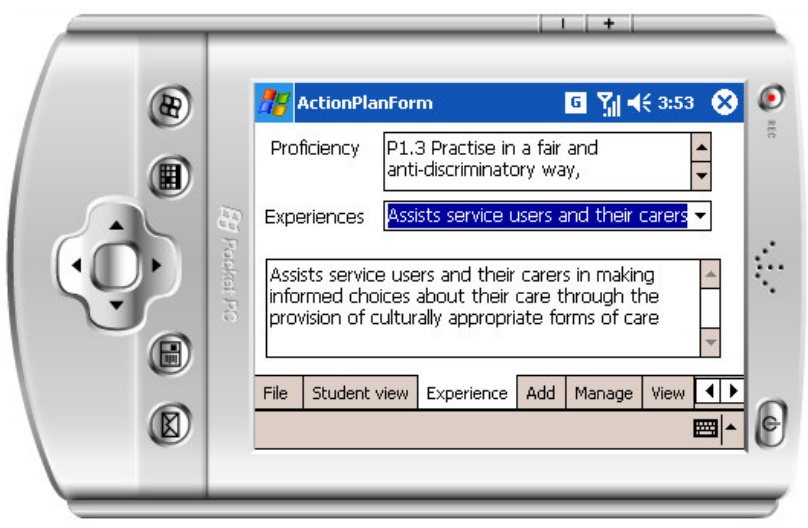

Figure 8: Action Plan (Experience)

The Mentors were provided with a Web Interface to access the Action Plan and follow a student's progress (Figure 10). 


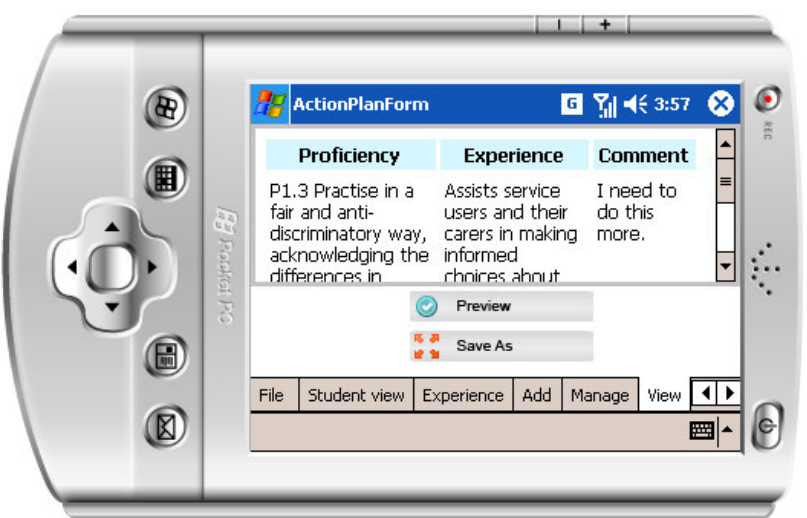

Figure 9: Action Plan (Student Final View)

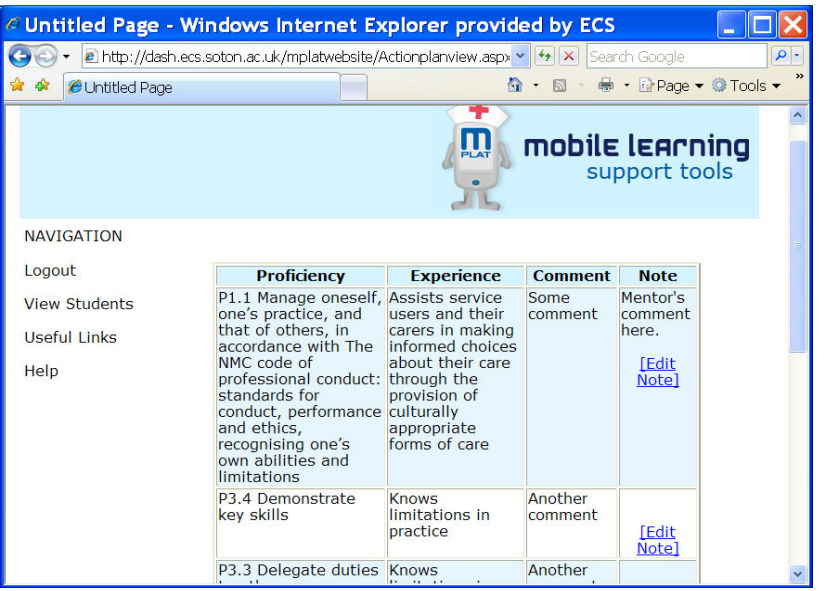

Figure 10: Mentor's View of Student's Progress

\section{Conclusions}

Students studying for degrees and diplomas in the health care professions generally undertake a number of clinical placements. Whilst in these placements clinical practitioners will assess the students' competence against a set of learning outcomes and give them ongoing feedback. Due to the workload of the supervising practitioners, the assessment processes can be fragile, which in turn can impinge on the students' learning.

At the same time students on placements are away from their usual learning environment, and it can be difficult for them to access their learning resources at the time that they discover the need.

In this paper we have proposed a toolkit for use with students sent on work placement. The toolkit has several important functions in allowing students to develop action plans based on their own self-assessment and placement profiles created by their mentors. This is possible due to a competency framework that underpins both the assessment and the profile.

The action plan acts as a focus for mentors and students at the start, midterm and final interview of each placement. It enables students to reflect on their progress in a structured way, and supports them in their understanding of the complex competency framework for their profession. In addition mentors can use web tools to keep up-to-date on their students' progress and prepare for their interviews.

We are currently running trials of our software with student nurses in placement at Southampton, and are preparing a similar trial at TVU and at Bournemouth and Poole College. Early indications are that the students not only use the mPLAT tools, but also use the provided PDA Phone to access internet resources, download documents, store notes and files as well as keep in contact with their colleagues throughout their placement, all of which are important considerations for learning.

We are just beginning a follow-on project to mPLAT called Remora, which will explore how the same mechanisms might be useful for social workers. We believe that reflection and planning based on a competency-model enables both the student and mentor to understand the whole competency space, which leads to the development of an informed action plan and therefore better support for both students and mentors.

\section{Acknowledgements}

This work is funded by the UK Joint Information Systems Committee (JISC).

\section{References}

1. Collins TG, "English Class on the Air: Mobile Language Learning with Cell Phones," Fifth IEEE International Conference on Advanced Learning Technologies (ICALT'05), pp. 402-403, 2005.

2. Nellie de Crom, "The "ME"-Learning Experience: PDA Technology and eLearning in Ecotourism at TUT", Fourth World Conference on Mobile Learning (mLearn), Oct 2005

3. Duffy, A (2004) Failing students - a qualitative study of factors that influence the decisions regarding assessment of students' http://www.nmc-uk.org/aArticle.aspx? ArticleID $=1675$ accessed June $5^{\text {th }} 2006$

4. Larman, C. (2004). Agile and Iterative Development: A manager's guide. Pearson Education.

5. McMillan J, "Seven Reasons Why mLearning Doesn't Work", Fourth World Conference on Mobile Learning (mLearn), Oct 2005

6. Sloan HL, Delahoussaye CP. Clinical application of the Omaha system with the Nightingale Tracker: a community health nursing student home visit program. Nurse Educ. 2003 Jan-Feb; 28(1):15-7.

7. Weal, M. J., Cruickshank, D. G., Michaelides, D. T., Millard, D. E., De Roure, D. C., Halloran, J., Hornecker, E. and Fitzpatrick, G. (2006) A persistent infrastructure for augmented field trips. In Proceedings of Ed-Media 06 Orlando, Florida, USA. 